\title{
Investigation into Multi-Temporal Scale Complexity of Streamflows and Water Levels in the Poyang Lake Basin, China
}

\author{
Feng Huang ${ }^{1,2, *}$, Xunzhou Chunyu ${ }^{1,2}$, Yuankun Wang ${ }^{3}$, Yao Wu ${ }^{2,4}$, Bao Qian ${ }^{5}$, Lidan Guo ${ }^{6}$, \\ Dayong Zhao ${ }^{1,2}$ and Ziqiang Xia ${ }^{1,2}$ \\ 1 State Key Laboratory of Hydrology-Water Resources and Hydraulic Engineering, Hohai University, \\ Nanjing 210098, China; zodiacnix@163.com (X.C.); dyzhao@hhu.edu.cn (D.Z.); zqxia@hhu.edu.cn (Z.X.) \\ 2 College of Hydrology and Water Resources, Hohai University, Nanjing 210098, China; wuyao@jxsl.gov.cn \\ 3 School of Earth Sciences and Engineering, Nanjing University, Nanjing 210023, China; \\ yuankunw@nju.edu.cn \\ 4 Poyang Lake Hydro Project Construction Office of Jiangxi Province, Nanchang 330046, China \\ 5 Bureau of Hydrology, Changjiang River Water Resources Commission, Wuhan 430012, China; \\ jacber@163.com \\ 6 International River Research Centre, Hohai University, Nanjing 210098, China; ldguohhu@163.com \\ * Correspondence: hfeng0216@163.com; Tel./Fax: +86-25-8378-6845
}

Academic Editors: Huijuan Cui, Bellie Sivakumar and Vijay P. Singh

Received: 24 December 2016; Accepted: 9 February 2017; Published: 10 February 2017

\begin{abstract}
The streamflow and water level complexity of the Poyang Lake basin has been investigated over multiple time-scales using daily observations of the water level and streamflow spanning from 1954 through 2013. The composite multiscale sample entropy was applied to measure the complexity and the Mann-Kendall algorithm was applied to detect the temporal changes in the complexity. The results show that the streamflow and water level complexity increases as the time-scale increases. The sample entropy of the streamflow increases when the time-scale increases from a daily to a seasonal scale, also the sample entropy of the water level increases when the time-scale increases from a daily to a monthly scale. The water outflows of Poyang Lake, which is impacted mainly by the inflow processes, lake regulation, and the streamflow processes of the Yangtze River, is more complex than the water inflows. The streamflow and water level complexity over most of the time-scales, between the daily and monthly scales, is dominated by the increasing trend. This indicates the enhanced randomness, disorderliness, and irregularity of the streamflows and water levels. This investigation can help provide a better understanding to the hydrological features of large freshwater lakes. Ongoing research will be made to analyze and understand the mechanisms of the streamflow and water level complexity changes within the context of climate change and anthropogenic activities.
\end{abstract}

Keywords: complexity; streamflow; water level; composite multiscale sample entropy; trend; Poyang Lake basin

\section{Introduction}

The complexity of a hydrological time series, e.g., precipitation, streamflow, and water level means that there is a degree of uncertainty, randomness, or irregularity of the time series. Many researchers have studied the hydrological complexity [1-5]. Chou analyzed the complexity of the correlation between rainfall and runoff, using the multiscale entropy approach, and found that: (1) the entropy measures of rainfall are higher than those of runoff at all scale factors; (2) the entropy measures of the runoff coefficient series lie between the entropy measures of the rainfall and runoff at various scale 
factors; and (3) the entropy values of rainfall, runoff and runoff coefficient series increase as scale factors increase. Liu et al. studied the complexity features of regional groundwater depth and found that human activities are the main driving force, causing the complexity of regional groundwater depth [6]. However, there seems to have been few attempts made to investigate the hydrological complexities of large lakes. Therefore, this study looks to the Poyang Lake basin as the study area and investigates its streamflow and water level complexity.

Poyang Lake, which is located in the Yangtze River basin, is the largest freshwater lake in China. The lake is the major body of water in an important global ecoregion, and plays an important role in maintaining the water resources of the Yangtze River and a healthy aquatic ecosystem in the region [7]. The hydrological processes of Poyang Lake are essential to the lacustrine and wetland ecosystems; and the disturbance of hydrological processes may break the longstanding ecological balance and influence the distinctive biodiversity have in this region [8]. The hydrological changes of Poyang Lake have attracted worldwide attention [9-11]. The Poyang Lake basin has experienced six extreme droughts during the past 60 years, thus resulting in the reduction of water resources from the five tributaries flowing into Poyang Lake [12]. The Three Gorges Reservoir has changed the Yangtze River streamflow and has further impacted the interrelationship between the Yangtze River and Poyang Lake [13]. Since the start of operations of the Three Gorges Reservoir, the seasonal water level of Poyang Lake has had a great magnitude of fluctuation [14].

Based on these previous studies, the present study investigates the hydrological changes of Poyang Lake from another perspective: hydrological complexity. Using the streamflow and water level data in the Poyang Lake basin from 1954 to 2013, this study aims to accomplish the following objectives: to investigate the streamflow and water level complexity over various time-scales; and secondly to detect the temporal changes in the streamflow and water level complexity. The first objective will reveal the streamflow and water level complexity changes versus the time-scale changes. Will the complexity increase, keep stable or decrease when the time-scale increases from a daily scale to a seasonal scale? The second objective will reveal the streamflow and water level complexity changes in the recent 60 years. The 1954-2013 streamflows and water levels are divided into 51 subseries. The complexity of each subseries is analyzed for a specific time-scale, and a complexity series can be obtained. The trends in the complexity series are further investigated to reveal what the temporal changes are. The results will add an understanding to the hydrological features and the changes of Poyang Lake and will also provide scientific references for other similar large freshwater lakes.

\section{Study Area and Data}

Poyang Lake is located in the Jiangxi Province in the middle to lower reaches of the Yangtze River. It receives inflows from five main tributaries: the Ganjiang, Fuhe, Xinjiang, Raohe, and Xiushui rivers. The lake exchanges water with the Yangtze River through a narrow channel in the north (Figure 1). Six hydrometric stations (Table 1) monitor the inflow processes from the tributaries, and one hydrometric station (Hukou) monitors the water exchanges of the Poyang Lake and the Yangtze River. The streamflows of the Hukou station have both positive and negative values. Recorded positive values are when the lake discharges into the river. When the river water discharges into the lake, the streamflow data of the Hukou station are recorded as negative values. Because the streamflow data is dominated by the positive values, the streamflow processes at the Hukou station are described as the outflow processes of Poyang Lake. Four hydrometric stations monitor the water levels of Poyang Lake. The hydrological data are daily recorded and the period of all hydrological data spans from 1954 through 2013. 

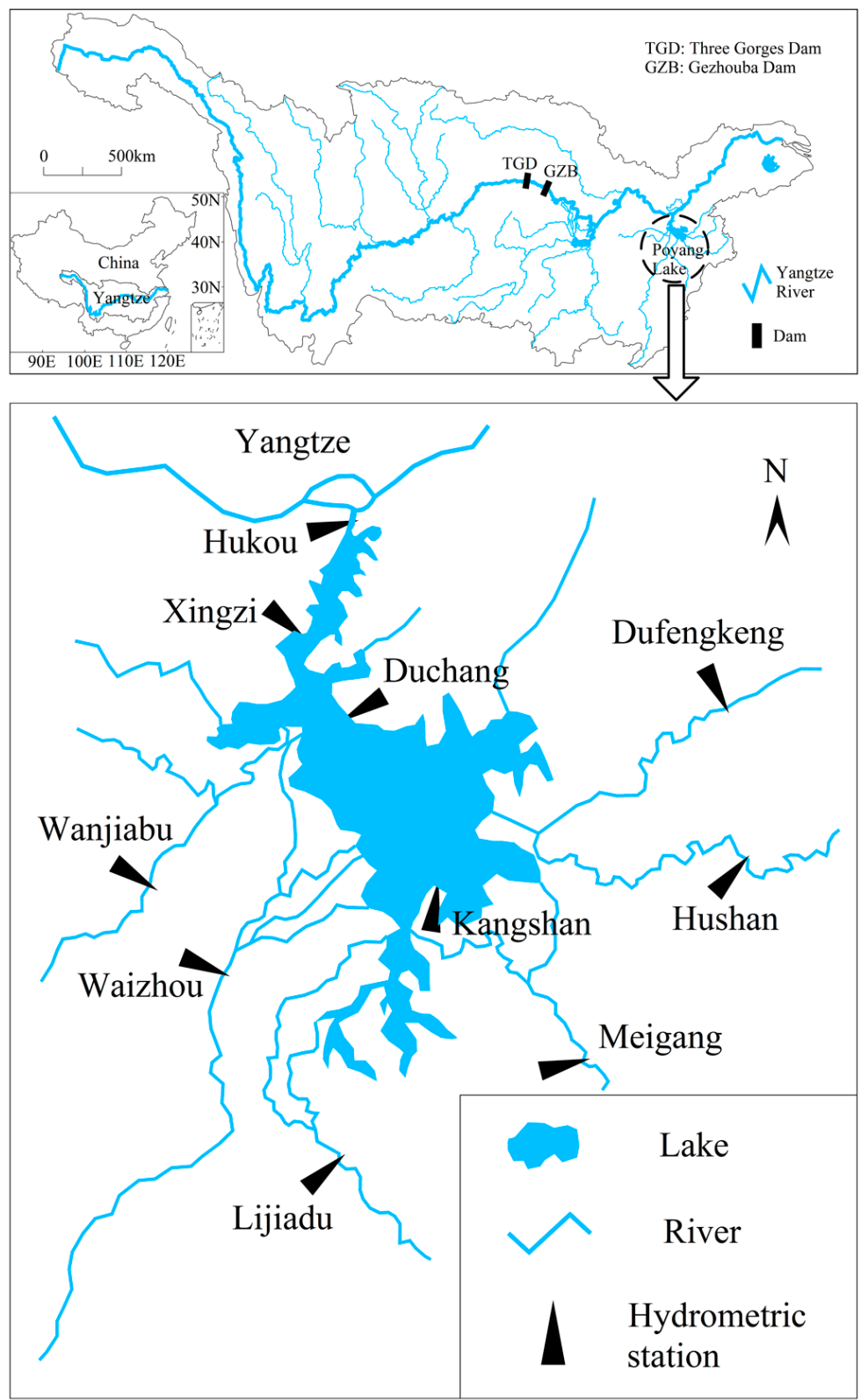

Figure 1. Locations of Poyang Lake and the hydrometric stations.

Table 1. Hydrometric stations in the Poyang Lake basin.

\begin{tabular}{|c|c|c|c|c|}
\hline $\begin{array}{l}\text { Hydrometric } \\
\text { Station }\end{array}$ & Data Type & Location & Longitude and Latitude & $\begin{array}{c}\text { Drainage Area } \\
\left(\mathrm{km}^{2}\right)\end{array}$ \\
\hline Waizhou & Streamflow & Ganjiang River & {$\left[115^{\circ} 50^{\prime} \mathrm{E}, 28^{\circ} 38^{\prime} \mathrm{N}\right]$} & 80,948 \\
\hline Lijiadu & Streamflow & Fuhe River & {$\left[116^{\circ} 10^{\prime} \mathrm{E}, 28^{\circ} 13^{\prime} \mathrm{N}\right]$} & 15,811 \\
\hline Meigang & Streamflow & Xinjiang River & {$\left[116^{\circ} 49^{\prime} \mathrm{E}, 28^{\circ} 26^{\prime} \mathrm{N}\right]$} & 15,535 \\
\hline Hushan & Streamflow & Raohe River & {$\left[117^{\circ} 16^{\prime} \mathrm{E}, 28^{\circ} 55^{\prime} \mathrm{N}\right]$} & 6374 \\
\hline Dufengkeng & Streamflow & Raohe River & {$\left[117^{\circ} 12^{\prime} \mathrm{E}, 2^{\circ} 16^{\prime} \mathrm{N}\right]$} & 5013 \\
\hline Wanjiabu & Streamflow & Xiushui River & {$\left[115^{\circ} 39^{\prime} \mathrm{E}, 28^{\circ} 51^{\prime} \mathrm{N}\right]$} & 3548 \\
\hline Kangshan & Water level & Poyang Lake & {$\left[116^{\circ} 25^{\prime} \mathrm{E}, 28^{\circ} 53^{\prime} \mathrm{N}\right]$} & / \\
\hline Duchang & Water level & Poyang Lake & {$\left[116^{\circ} 11^{\prime} \mathrm{E}, 29^{\circ} 15^{\prime} \mathrm{N}\right]$} & / \\
\hline Xingzi ${ }^{\circ}$ & Water level & Poyang Lake & {$\left[116^{\circ} 2^{\prime} \mathrm{E}, 29^{\circ} 27^{\prime} \mathrm{N}\right]$} & / \\
\hline Hukou & Streamflow, Water level & Poyang Lake & {$\left[116^{\circ} 13^{\prime} \mathrm{E}, 29^{\circ} 45^{\prime} \mathrm{N}\right]$} & 162,225 \\
\hline
\end{tabular}




\section{Methodology}

\subsection{Analysis Procedure}

The streamflow and water level complexity are measured by sample entropy. Composite multiscale sample entropy is applied to reveal the streamflow and water level complexity over various time-scales. Both static and dynamic sample entropies over various time-scales are calculated to investigate the multiscale complexity [15]. The static sample entropy reveals different complexities over various time-scales, and the dynamic sample entropy reveals temporal complexity trends over various time-scales. First, the static sample entropy is analyzed, which ignores the complexity changes over time. The composite multiscale sample entropy is calculated using the entire hydrological data records. Second, the dynamic sample entropy is analyzed, which reflects the complexity changes over time. To obtain how the streamflow and water level complexity changed over time, a ten year sliding window was selected for the hydrological data, which divides the original entire hydrological data records. Thus, the 1954-2013 series is divided into 51 subseries: 1954-1963, 1955-1964, 1956-1965, ..., 2002-2011, 2003-2012, and 2004-2013. The composite multiscale sample entropy is calculated using each subseries, respectively. A sample entropy series can be obtained for a time-scale, which reflects the complexity changes over time. Temporal trends in the sample entropy series are further analyzed applying the Mann-Kendall algorithm.

\subsection{Sample Entropy}

The hydrological complexity means the degree of uncertainty or the rate of information production of the hydrological series, e.g., the streamflow and the water level. Techniques for measuring the hydrological complexity typically involve the calculations of: the Lyapunov exponent, correlation dimension, fractal dimension, Kolmogorov-Sinai entropy, spectral entropy, approximate entropy, and sample entropy [5]. The approximate entropy calculation solves the problem of insufficient number of data points, and is applicable to noisy, medium-sized data sets. However, it lacks relative consistency and its results depend on data length. Improved on the basis of the approximate entropy calculation, the sample entropy calculation is an unbiased estimation of the conditional probability that two similar sequences of $m$ consecutive data points ( $m$ is the embedded dimension) will remain similar when one more consecutive point is included [16]. It is largely independent of data length and keeps relative consistency without counting self-matches [17]. For a time series of $N$ points $\{x(i), i=1,2, \ldots, N\}$, the sample entropy (SampEn) is calculated by the following steps:

(1) Constitute vectors of $m$ dimensions:

$$
X(i)=\{x(i), x(i+1), \ldots, x(i+m-1)\} \quad(i=1,2, \ldots, N-m+1)
$$

(2) Define the Euclidean distance between $X(i)$ and $X(j), d[X(i), X(j)]$ as the maximum absolute difference of their corresponding scalar components:

$$
d[X(i), X(j)]=\operatorname{Max}_{k=0 \rightarrow m-1}\{|X(i+k)-X(j+k)|\}
$$

(3) Take $n_{i}^{m}$ as the number of sequences in the time series that match (without self-matching) the template with the length $m$ within the tolerance criterion $r$. Then, define $C_{i}^{m}(r)$ and $C^{m}(r)$ separately as the following equations:

$$
\begin{gathered}
C_{i}^{m}(r)=\frac{n_{i}^{m}}{N-m} \\
C^{m}(r)=\frac{1}{N-m+1} \sum_{i=1}^{N-m+1} C_{i}^{m}(r)
\end{gathered}
$$

(4) Change the dimension of the vector $X(i)$ to $m+1$ and calculate $C^{m+1}(r)$ similarly. 
(5) Finally, SampEn is defined as:

$$
S a m p E n=-\ln \frac{C^{m+1}(r)}{C^{m}(r)}
$$

When calculating the sample entropy, the template length $m$ is set to be 2 , and the tolerance criterion $r$ is set to be $0.15 \sigma$, where $\sigma$ denotes the standard deviation of the original time series.

\subsection{Composite Multiscale Sample Entropy}

To completely measure the underlying dynamics of complex systems under consideration, displaying their disorderliness over multiple time-scales, Costa et al. proposed the multiscale entropy algorithm. This algorithm calculates the sample entropy of a time series over various time-scales [18]. Although the multiscale entropy algorithm has been successfully applied in a number of different fields (including the analysis of the human gait dynamics, heart rate variability, rainfall, and river streamflow), it encounters a problem in that the statistical reliability of the sample entropy of the coarse-grained series is reduced as the time-scale is increased. To overcome this limitation, Wu et al. proposed the concept of composite multiscale sample entropy, which better presents data in both simulation and real world data analysis [19].

The principles and calculation procedures of the composite multiscale sample entropy can be found in $\mathrm{Wu}$ et al. [19]. When the sample entropy is calculated with the template length $m=2$, there are two and three coarse-grained time series divided from the original time series for scale factors of 2 and 3, respectively. The $k$ th coarse-grained time series for a scale factor of $\tau, y_{k}^{(\tau)}$ is defined as:

$$
y_{k, j}^{(\tau)}=\frac{1}{\tau} \sum_{i=(j-1) \tau+k}^{j \tau+k-1} x_{i} \quad\left(1 \leq j \leq \frac{N}{\tau}, 1 \leq k \leq \tau\right)
$$

At a scale factor of $\tau$, the sample entropy of all coarse-grained time series are calculated and the composite multiscale sample entropy (CMSE) value is defined as the means of $\tau$ entropy values:

$$
\operatorname{CMSE}(x, \tau, m, r)=\frac{1}{\tau} \sum_{k=1}^{\tau} \operatorname{SampEn}\left(y_{k}^{(\tau)}, m, r\right)
$$

\subsection{Mann-Kendall Algorithm}

The trend detection methods include Spearman's rho test, Mann-Kendall test, seasonal Kendall test, linear regression test, and so on [20]. One of the most favored trend detection methods is the Mann-Kendall algorithm, which has been employed to detect the trends in hydrological series, including precipitation [21], runoff [22], sample entropy [5], coefficient of variation, and concentration degree [23]. Detailed information on the Mann-Kendall algorithm can be found in the published papers [24]. The Mann-Kendall test is based on the test statistic S:

$$
S=\sum_{i=1}^{n-1} \sum_{j=i+1}^{n} \operatorname{sgn}\left(x_{j}-x_{i}\right)
$$

where the $x_{j}$ and $x_{i}$ are the sequential data values, $n$ is the length of the data set, and:

$$
\operatorname{sgn}(\theta)=\left\{\begin{array}{rll}
1 & \text { if } & \theta>0 \\
0 & \text { if } & \theta=0 \\
-1 & \text { if } & \theta<0
\end{array}\right.
$$

When $n \geq 8$, the statistic $S$ is approximately normally distributed with the mean and the variance as follows: 


$$
\begin{gathered}
E(S)=0 \\
\operatorname{Var}(S)=\frac{n(n-1)(2 n+5)-\sum_{i=1}^{n} t_{i} i(i-1)(2 i+5)}{18}
\end{gathered}
$$

where $t_{i}$ is the number of ties of extent $i$. The standardized test statistic $Z$ is computed by

$$
Z= \begin{cases}\frac{S-1}{\sqrt{\operatorname{Var}(S)}} & S>0 \\ 0 & S=0 \\ \frac{S+1}{\sqrt{\operatorname{Var}(S)}} & S<0\end{cases}
$$

$Z$ follows the standard normal distribution with a mean of zero and variance of one. A positive or negative value of $Z$ represents an increasing or decreasing trend, respectively. In a two-tailed test, the null hypothesis is no trend, which can be rejected at significance level $\alpha$ if $|Z|>Z_{\alpha / 2}$. The $Z_{\alpha / 2}$ is the value of the standard normal distribution with an exceedance probability of $\alpha / 2$. The significance level $\alpha$ is set to be 0.05 in this study.

\section{Results and Discussion}

\subsection{Multiscale Complexity of Streamflows}

Figure 2 displays the composite multiscale sample entropy of the inflow and outflow data of Poyang Lake, respectively. The variations of sample entropy versus time-scale are similar. The sample entropy is increasing when the time-scale is increasing, revealing that the time series have obvious self-similarity and great complexity [25]. Similar results, i.e., the complexity of streamflows is increasing as the time-scale is increasing, have also been found in the multiscale entropy analysis of the streamflows of the Mississippi River in the United States [4], the East River in China [3], and the Yangtze River in China [2]. These previous studies attribute this phenomenon to the existence of the long-range correlation of the streamflow records. Larger sample entropy reflects more randomness and complicated systems, and vice versa. When the time-scale is increasing, the increasing sample entropy indicates an increase in the uncertainty and disorderliness, and a lessened regularity and predictability.
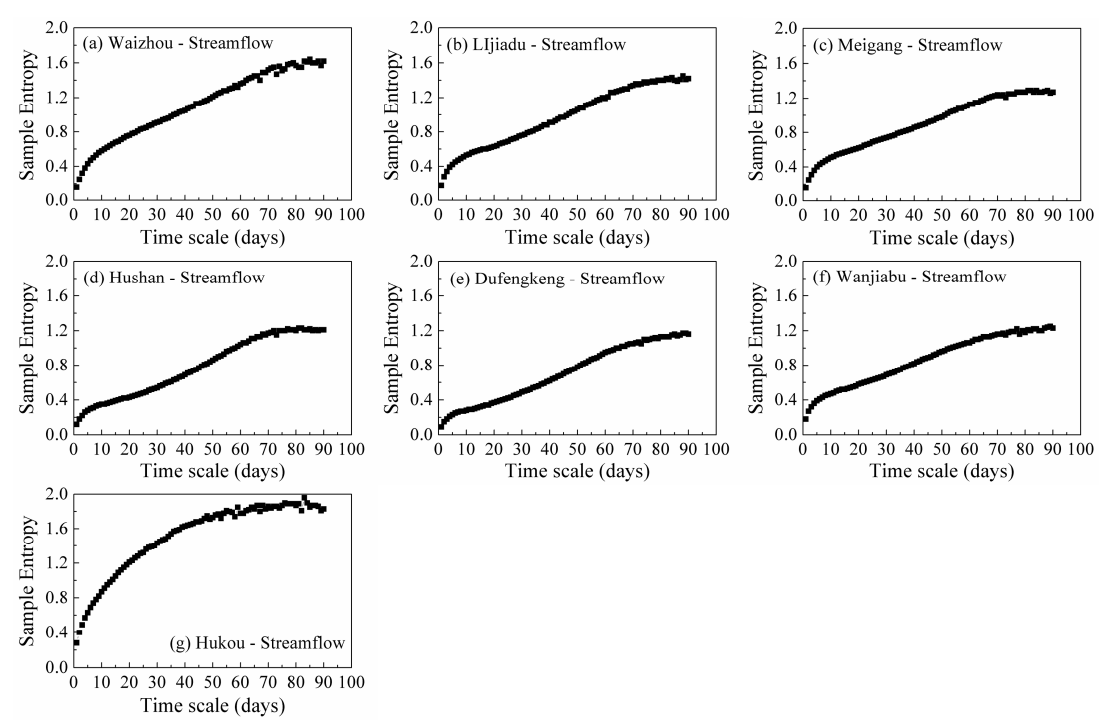

Time scale (days)

Figure 2. Composite multiscale sample entropy of the streamflows of Poyang Lake.

When comparing Figures $2 a-f$ and $2 g$, it can be observed that the sample entropy values at different time-scales of the outflows are distributed above those of the inflows. When the sample 
entropy values of one time series are larger than those of another time series at most time-scales, it reveals that the former is more complex than the latter [26]. Figure 3 compares the average sample entropy of the inflows and outflows of Poyang Lake. The average sample entropy is the mean value of sample entropies at various time-scales. The average sample entropy of the streamflow data at the Hukou station is the largest in Figure 3, indicating that the outflows are more complex than the inflows of Poyang Lake. Due to the spatial and temporal distribution of precipitation, the Yangtze River and Poyang Lake have complex river-lake interactions. The streamflow processes at the Hukou station are determined by the water level in Poyang Lake (relative to the water level in the Yangtze River), which in turn is affected by both the inflow processes and the outflow processes [27]. Poyang Lake acts as a buffer at varying degrees for the Yangtze River streamflow. When the water level of the Yangtze River rises during the flood season, the Poyang Lake helps to absorb some flood and mitigates the peak streamflow of the Yangtze River [13]; hence, the streamflow processes at the Hukou station are more complex than the streamflow processes at the hydrometric stations of the tributaries.

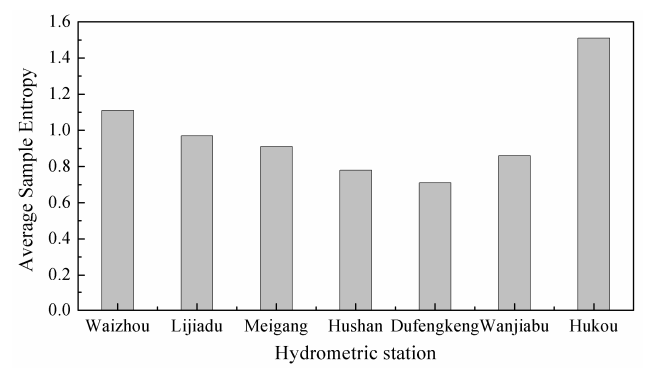

Figure 3. Average sample entropy of the streamflows of Poyang Lake.

\subsection{Multiscale Complexity of Water Levels}

Figure 4 displays the composite multiscale sample entropy of the water levels of Poyang Lake. The water levels, monitored at the Kangshan, Duchang, Xingzi, and Hukou stations, have similar change patterns in term of sample entropy versus time-scale. The sample entropy increases rapidly until the time-scale reaches about 30 days, after that, the increase becomes small. The sample entropy becomes relatively stable when the time-scale reaches about 30 days. The randomness and irregularity of the water levels are greater with the increased time-scale from a daily to a monthly scale. The water levels have a relatively stable complexity when the time-scale is larger than 30 days, indicating relatively stable regularity and predictability. The water level of Poyang Lake is an integrated response to the inflow, outflow, precipitation, evaporation, leakage, water withdraw, and topography of the lake. Hence, the complexity of the water levels may not be identical to that of the inflows and outflows.
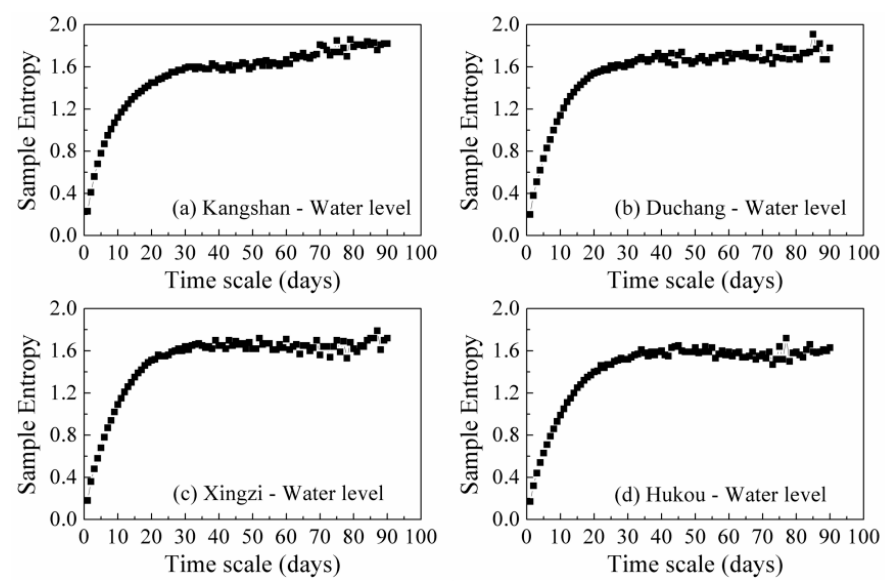

Figure 4. Composite multiscale sample entropy of the water levels of Poyang Lake. 


\subsection{Temporal Changes in Complexity of Streamflows and Water Levels}

Figure 5 shows the statistical $Z$ values of the Mann-Kendall algorithm, which reveals temporal trends in the complexity of the inflows and outflows of Poyang Lake. Figure 6 displays temporal variations in the complexity of the daily streamflows as examples. The sample entropy series of various time-scales at the Waizhou, Lijiadu, Meigang, Hushan, and Wanjiabu stations are dominated by increasing trends, indicating the increased inflow complexity of Poyang Lake. The sample entropy series of various time-scales at the Dufengkeng station are relatively stable. Only a significant decreasing trend is detected at the daily scale. The absolute $Z$ values of the other time-scales are below the 0.05 significance level, indicating no significant trend. The sample entropy series over different time-scales at the Hukou station are also featured by increasing trends, indicating the increased outflow complexity of Poyang Lake.

Figure 7 shows temporal trends in the multiscale complexity of the water levels of Poyang Lake. Figure 8 displays temporal variations in the complexity of the daily water levels as examples. The sample entropy series over different time-scales are characterized by increasing tends, indicating the greater irregularity and randomness of the water levels.
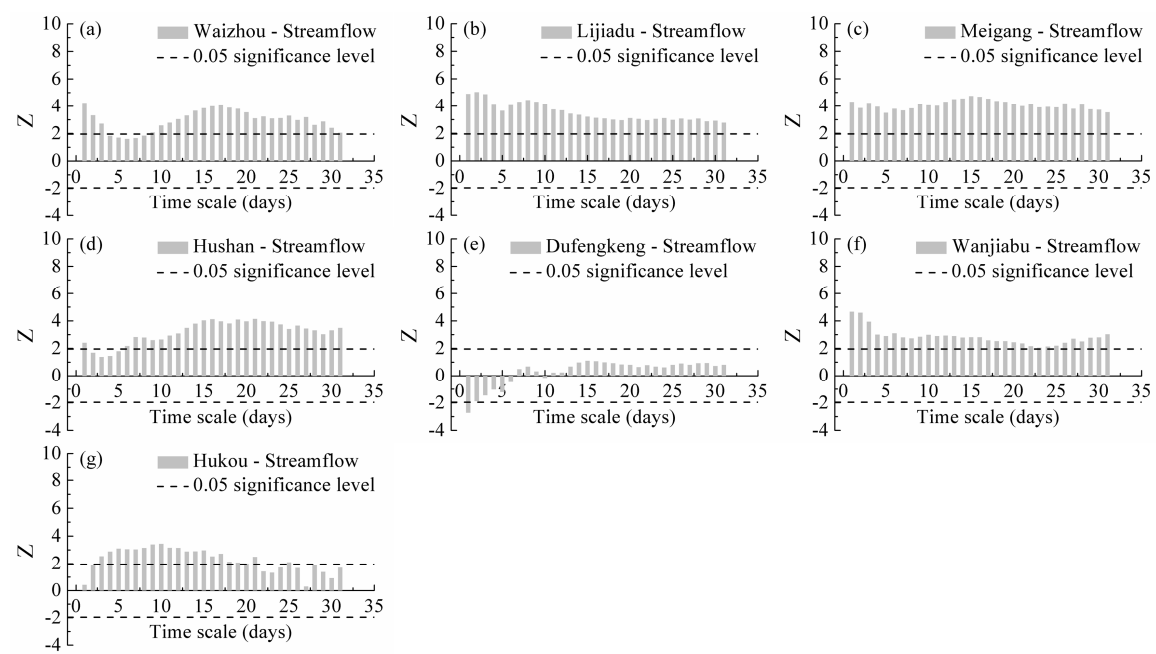

Figure 5. Trends in multiscale complexity of the streamflows of Poyang Lake.
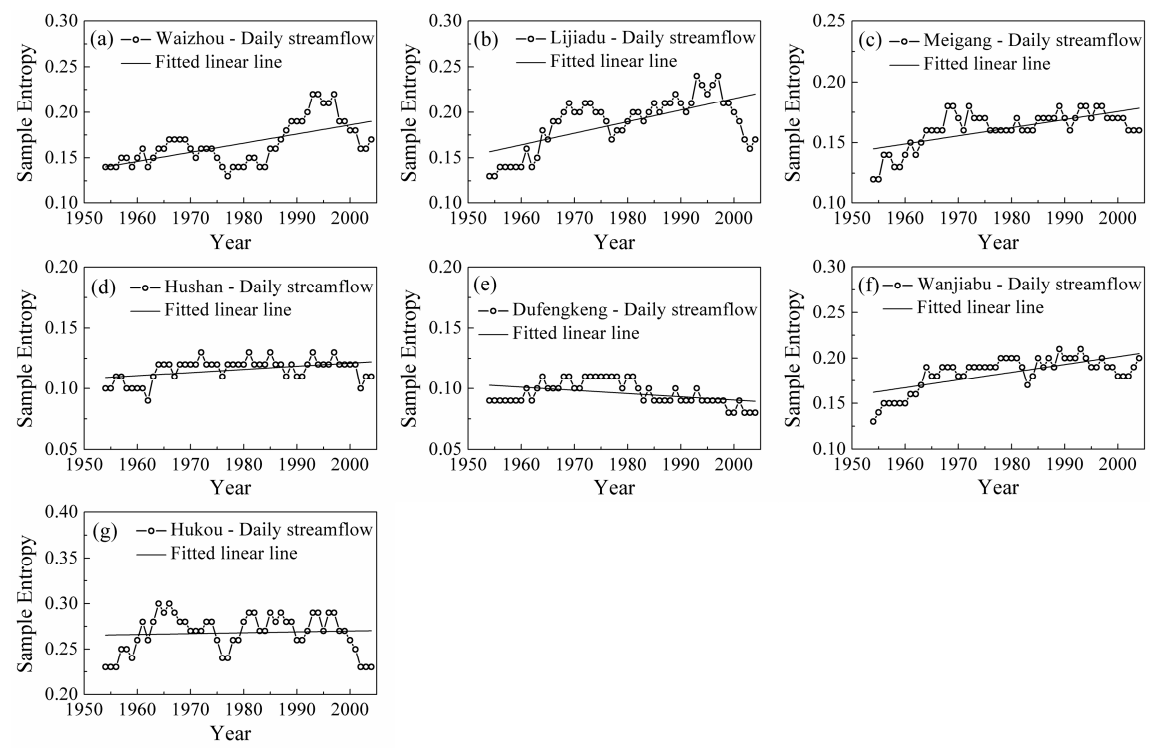

Figure 6. Temporal changes in complexity of the daily streamflows of Poyang Lake. 

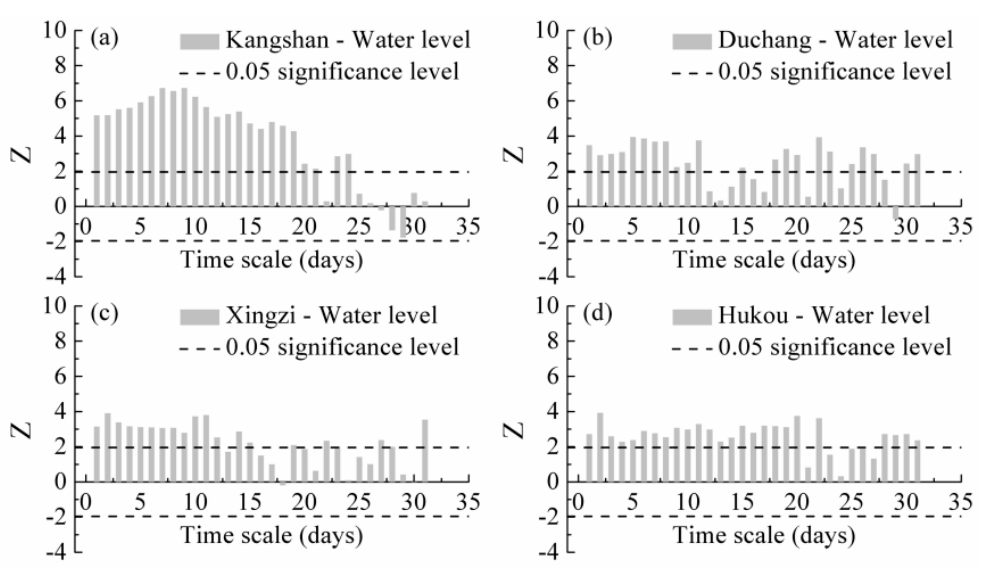

Figure 7. Trends in multiscale complexity of the water levels of Poyang Lake.
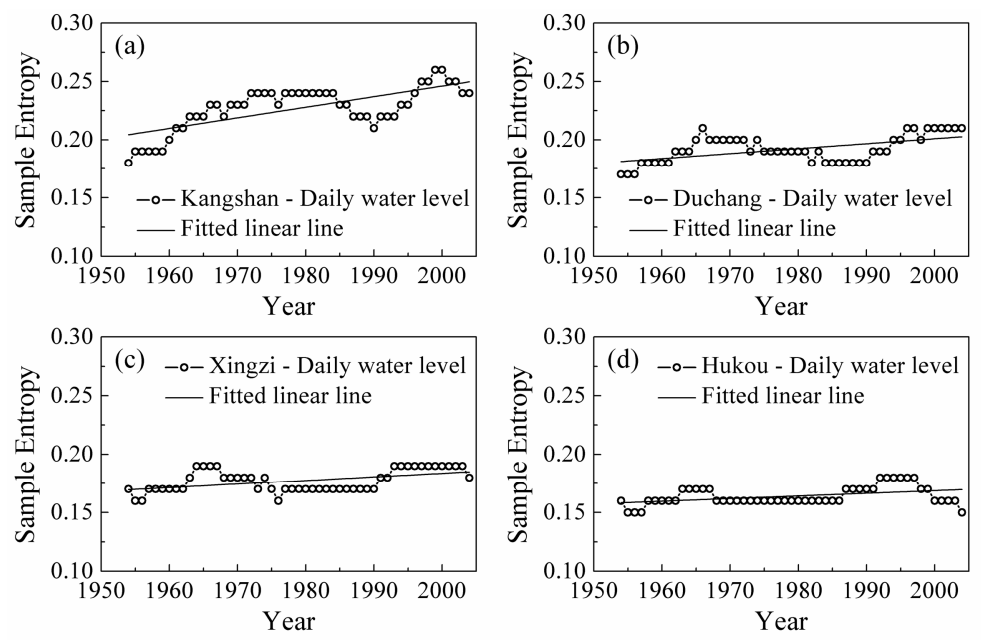

Figure 8. Temporal changes in complexity of the daily water levels of Poyang Lake.

\subsection{Discussion on Temporal Changes in Streamflow and Water Level Complexity}

Hydrological systems are open, dynamic, complex, giant, and nonlinear compound systems. For the Poyang Lake basin, the outputs of this hydrological system, which are described by the streamflows and the water levels, are highly nonlinear and complex, and are significantly impacted by both climate change and anthropogenic activities. Precipitation is a dominant impact factor of the Poyang Lake hydrological system. In the Jiangxi province, Huang et al. found remarkable differences among the meteorological stations with negative and positive precipitation trends at the annual, seasonal, and monthly scales. Significant increasing trends are mainly found during winter and summer, while significant decreasing trends are mostly observed during autumn [21]. Xiao et al. analyzed the spatial and temporal characteristics of rainfall across the Ganjiang River basin, the largest sub-basin of the Poyang Lake basin, and found significant increasing trends in the annual total rainfall amount [28]. Temperature is another relevant factor which directly affects evaporation. According to a study by Tao et al. of the Poyang Lake basin, the annual mean of the daily minimum temperature has increased significantly, while no significant trend has been detected in the annual mean of daily maximum temperature; thus, resulting in a significant decrease in the diurnal temperature range [29]. Ye et al. detected a significant decreasing trend in the annual reference evapotranspiration in the Poyang Lake basin [30]. Based on prior studies, more attention will be paid in future research to elucidate the complexity features of precipitation, temperature, evaporation, and the mechanisms on 
how the complexity of those impact factors affect the complexity of the outputs of the Poyang Lake hydrological system.

Including the climate factors, anthropogenic activities are also very important factors affecting the hydrological processes. The anthropogenic activities mainly include dam and reservoir construction, water withdraw, land use, and land cover changes, along with sand extraction from river and lake beds. Mei et al. argued that the average contributions of precipitation variation, human activities in the Poyang Lake catchment, and the Three Gorges Reservoir regulation to the Poyang Lake recession can be quantified as $39.1 \%, 4.6 \%$ and $56.3 \%$, respectively [31]. Zhang et al. found that human-induced and climate-induced influences on streamflows are different in the five Poyang Lake sub-basins. Climate change is the major driving factor for the streamflow increases within the Ganjiang, Xinjiang, and Raohe River basins; however, anthropogenic activities are the principal driving factors for the streamflow increase of the Xiushui River basin and for the streamflow decrease of the Fuhe River basin [32].

Dam and reservoir construction is one of the most important anthropogenic activities, and has attracted worldwide attention due to its significant influence on hydrological processes [33-37]. In the Poyang Lake basin, thousands of reservoirs have been constructed, including 27 large reservoirs $\left(>10^{8} \mathrm{~m}^{3}\right.$ in storage capacity) [11]. The reservoirs in the Poyang Lake basin may affect the Poyang Lake hydrological complexity. The reservoirs in the upper Yangtze River basin, especially the Three Gorges Reservoir, may also affect the Poyang Lake hydrological complexity through disturbing the natural river-lake interrelationships. Some interesting conclusions have been obtained in terms of the impact of dam and reservoir construction on hydrological complexity. Huang et al. attributed the loss of streamflow complexity of the upper reaches of the Yangtze River to the underlying surface condition change, which has been influenced by human activities, especially reservoir construction. Huang et al. also argued that the reservoir operation makes the streamflow more regular and self-similar, leading to the streamflow complexity loss [5]. Similar conclusions were obtained in the hydrological complexity analysis of the Colorado River in the United States [38] and the Sao Francisco River in Brazil [39]. Those studies elucidated that dam and reservoir construction induced significant changes in streamflow dynamics, including an increase in regularity and a loss of complexity. However, the study in the East River (China) obtained the opposite conclusion. Zhou et al. argued that reservoir construction greatly increases the complexity of hydrological processes because of reservoir-induced noise of the streamflow [3]. More research is needed to systematically analyze the impact of reservoirs on hydrological complexity.

The enhancement of the streamflow and water level complexity in the Poyang Lake basin is the combined result of climate change and anthropogenic activities. Explaining how climate change and anthropogenic activities affect the hydrological complexity while at the same time distinguishing their individual contributions are our ongoing research objectives.

\section{Conclusions}

Based on the long term observed daily streamflow and water level data of Poyang Lake, the streamflow and water level complexity over various time-scales and its temporal changes are investigated using the composite multiscale sample entropy and the Mann-Kendall algorithm. The following conclusions can be drawn from the analysis:

(1) The streamflow and water level complexity increases when the time-scale increases. The sample entropy of the streamflows increases when the time-scale increases from the daily to seasonal scale. The sample entropy of the water levels increases when the time-scale increases from the daily to monthly scale.

(2) The complexity of the outflows is greater than that of the inflows. It may be caused by the complex river-lake interrelationships. The outflow processes of Poyang Lake are synthetically impacted by the inflow processes, lake regulation, and the streamflow processes of the Yangtze River. 
(3) Significant upward trends can be detected in the sample entropy series, which are calculated using the streamflow and water level data, for most time-scales between the daily to monthly scale. The increased sample entropy indicates the enhanced streamflow and water level complexity, which may be caused by both climate change and anthropogenic activities. The mechanisms of the hydrological complexity changes will be studied in ongoing research.

Acknowledgments: This work is supported by the National Natural Science Foundation Projects of China (grant numbers 41401011, 51309131,51679118, 41401010, and 41371098); Science and Technology Projects of Water Resources Department of Jiangxi Province (grant number KT201538); CRSRI Open Research Program (grant number CKWV2015237/KY); and Program for Changjiang Scholars and Innovative Research Team in University (grant number IRT13062). The authors acknowledge constructive comments from the editor and anonymous reviewers, which lead to improvement of the paper.

Author Contributions: The authors designed and performed the research together. Feng Huang wrote the draft of the paper. Xunzhou Chunyu, Yuankun Wang, Yao Wu, Bao Qian, Lidan Guo, Dayong Zhao and Ziqiang Xia made some comments and corrections. All authors have read and approved the final manuscript.

Conflicts of Interest: The authors declare no conflict of interest.

\section{References}

1. Sang, Y.F.; Wang, D.; Wu, J.C.; Zhu, Q.P.; Wang, L. Wavelet-Based Analysis on the Complexity of Hydrologic Series Data under Multi-Temporal Scales. Entropy 2011, 13, 195-210. [CrossRef]

2. Zhang, Q.; Zhou, Y.; Singh, V.P.; Chen, X.H. The influence of dam and lakes on the Yangtze River streamflow: long-range correlation and complexity analyses. Hydrol. Process. 2012, 26, 436-444. [CrossRef]

3. Zhou, Y.; Zhang, Q.; Li, K.; Chen, X.H. Hydrological effects of water reservoirs on hydrological processes in the East River (China) basin: Complexity evaluations based on the multi-scale entropy analysis. Hydrol. Process. 2012, 26, 3253-3262. [CrossRef]

4. Li, Z.W.; Zhang, Y.K. Multi-scale entropy analysis of mississippi river flow. Stoch. Environ. Res. Risk Assess. 2008, 22, 507-512. [CrossRef]

5. Huang, F.; Xia, Z.Q.; Zhang, N.; Zhang, Y.D.; Li, J. Flow-Complexity Analysis of the Upper Reaches of the Yangtze River, China. J. Hydrol. Eng. 2011, 16, 914-919. [CrossRef]

6. Liu, M.; Liu, D.; Liu, L. Complexity research of regional groundwater depth series based on multiscale entropy: a case study of Jiangsanjiang Branch Bureau in China. Environ. Earth Sci. 2013, 70, 353-361. [CrossRef]

7. Lai, X.J.; Liang, Q.H.; Jiang, J.H.; Huang, Q. Impoundment Effects of the Three-Gorges-Dam on Flow Regimes in Two China's Largest Freshwater Lakes. Water Resour. Manag. 2014, 28, 5111-5124. [CrossRef]

8. Cao, L.; Fox, A.D. Birds and people both depend on China's wetlands. Nature 2009, 460, 173. [CrossRef] [PubMed]

9. Zhao, G.J.; Hoermann, G.; Fohrer, N.; Zhang, Z.X.; Zhai, J.Q. Streamflow Trends and Climate Variability Impacts in Poyang Lake Basin, China. Water Resour. Manag. 2010, 24, 689-706. [CrossRef]

10. Ye, X.C.; Zhang, Q.; Liu, J.; Li, X.H.; Xu, C.Y. Distinguishing the relative impacts of climate change and human activities on variation of streamflow in the Poyang Lake catchment, China. J. Hydrol. 2013, 494, 83-95. [CrossRef]

11. Lai, X.J.; Huang, Q.; Zhang, Y.H.; Jiang, J.H. Impact of lake inflow and the Yangtze River flow alterations on water levels in Poyang Lake, China. Lake Reserv. Manag. 2014, 30, 321-330. [CrossRef]

12. Zhang, Z.X.; Chen, X.; Xu, C.Y.; Hong, Y.; Hardy, J.; Sun, Z.H. Examining the influence of river-lake interaction on the drought and water resources in the Poyang Lake basin. J. Hydrol. 2015, 522, 510-521. [CrossRef]

13. Guo, H.; Hu, Q.; Zhang, Q.; Feng, S. Effects of the Three Gorges Dam on Yangtze River flow and river interaction with Poyang Lake, China: 2003-2008. J. Hydrol. 2012, 416, 19-27. [CrossRef]

14. Dai, X.; Wan, R.R.; Yang, G.S. Non-stationary water-level fluctuation in China's Poyang Lake and its interactions with Yangtze River. J. Geogr. Sci. 2015, 25, 274-288. [CrossRef]

15. Chou, C.M. Complexity analysis of rainfall and runoff time series based on sample entropy in different temporal scales. Stoch. Environ. Res. Risk Assess. 2014, 28, 1401-1408. [CrossRef] 
16. Costa, M.; Peng, C.K.; Goldberger, A.L.; Hausdorff, J.M. Multiscale entropy analysis of human gait dynamics. Physica A 2003, 330, 53-60. [CrossRef]

17. Richman, J.S.; Moorman, J.R. Physiological time-series analysis using approximate entropy and sample entropy. Am. J. Physiol. Heart Circ. Physiol. 2000, 278, H2039-H2049. [PubMed]

18. Costa, M.; Goldberger, A.L.; Peng, C.K. Multiscale entropy analysis of complex physiologic time series. Phys. Rev. Lett. 2002, 89, 068102. [CrossRef] [PubMed]

19. Wu, S.D.; Wu, C.W.; Lin, S.G.; Wang, C.C.; Lee, K.Y. Time Series Analysis Using Composite Multiscale Entropy. Entropy 2013, 15, 1069-1084. [CrossRef]

20. Kundzewicz, Z.W.; Robson, A.J. Change detection in hydrological records-A review of the methodology. Hydrol. Sci. J. 2004, 49, 7-19. [CrossRef]

21. Huang, J.; Sun, S.L.; Zhang, J.C. Detection of trends in precipitation during 1960-2008 in Jiangxi province, southeast China. Theor. Appl. Clim. 2013, 114, 237-251. [CrossRef]

22. Zhao, Q.H.; Liu, S.L.; Deng, L.; Dong, S.K.; Yang, J.J.; Wang, C. The effects of dam construction and precipitation variability on hydrologic alteration in the Lancang River Basin of southwest China. Stoch. Environ. Res. Risk Assess. 2012, 26, 993-1011. [CrossRef]

23. Huang, F.; Xia, Z.Q.; Li, F.; Guo, L.D.; Yang, F.C. Hydrological Changes of the Irtysh River and the Possible Causes. Water Resour. Manag. 2012, 26, 3195-3208. [CrossRef]

24. Yue, S.; Pilon, P.; Cavadias, G. Power of the Mann-Kendall and Spearman's rho tests for detecting monotonic trends in hydrological series. J. Hydrol. 2002, 259, 254-271. [CrossRef]

25. Chou, C.M. Applying Multiscale Entropy to the Complexity Analysis of Rainfall-Runoff Relationships. Entropy 2012, 14, 945-957. [CrossRef]

26. Costa, M.; Goldberger, A.L.; Peng, C.K. Multiscale entropy analysis of biological signals. Phys. Rev. E 2005, 71, 021906. [CrossRef] [PubMed]

27. Zhang, Q.; Li, L.; Wang, Y.G.; Werner, A.D.; Xin, P.; Jiang, T.; Barry, D.A. Has the Three-Gorges Dam made the Poyang Lake wetlands wetter and drier? Geophys. Res. Lett. 2012, 39, L20402. [CrossRef]

28. Xiao, Y.; Zhang, X.; Wan, H.; Wang, Y.Q.; Liu, C.; Xia, J. Spatial and temporal characteristics of rainfall across Ganjiang River Basin in China. Meteorol. Atmos. Phys. 2016, 128, 167-179. [CrossRef]

29. Tao, H.; Fraedrich, K.; Menz, C.; Zhai, J.Q. Trends in extreme temperature indices in the Poyang Lake Basin, China. Stoch. Environ. Res. Risk Assess. 2014, 28, 1543-1553. [CrossRef]

30. Ye, X.C.; Li, X.H.; Liu, J.; Xu, C.Y.; Zhang, Q. Variation of reference evapotranspiration and its contributing climatic factors in the Poyang Lake catchment, China. Hydrol. Process. 2014, 28, 6151-6162. [CrossRef]

31. Mei, X.F.; Dai, Z.J.; Du, J.Z.; Chen, J.Y. Linkage between Three Gorges Dam impacts and the dramatic recessions in China's largest freshwater lake, Poyang Lake. Sci. Rep. 2015, 5, 18197. [CrossRef] [PubMed]

32. Zhang, Q.; Liu, J.Y.; Singh, V.P.; Gu, X.H.; Chen, X.H. Evaluation of impacts of climate change and human activities on streamflow in the Poyang Lake basin, China. Hydrol. Process. 2016, 30, 2562-2576. [CrossRef]

33. Huang, F.; Chen, Q.H.; Li, F.; Zhang, X.; Chen, Y.Y.; Xia, Z.Q.; Qiu, L.Y. Reservoir-Induced Changes in Flow Fluctuations at Monthly and Hourly Scales: Case Study of the Qingyi River, China. J. Hydrol. Eng. 2015, 20, 05015008. [CrossRef]

34. Yang, T.; Zhang, Q.; Chen, Y.D.; Tao, X.; Xu, C.Y.; Chen, X. A spatial assessment of hydrologic alteration caused by dam construction in the middle and lower Yellow River, China. Hydrol. Process. 2008, 22, 3829-3843. [CrossRef]

35. Chen, Q.H.; Zhang, X.; Chen, Y.Y.; Li, Q.F.; Qiu, L.Y.; Liu, M. Downstream effects of a hydropeaking dam on ecohydrological conditions at subdaily to monthly time scales. Ecol. Eng. 2015, 77, 40-50. [CrossRef]

36. Wang, Y.K.; Wang, D.; Wu, J.C. Assessing the impact of Danjiangkou reservoir on ecohydrological conditions in Hanjiang river, China. Ecol. Eng. 2015, 81, 41-52. [CrossRef]

37. Wang, Y.K.; Rhoads, B.L.; Wang, D. Assessment of the flow regime alterations in the middle reach of the Yangtze River associated with dam construction: Potential ecological implications. Hydrol. Process. 2016, 30, 3949-3966. [CrossRef] 
38. Serinaldi, F.; Zunino, L.; Rosso, O.A. Complexity-entropy analysis of daily stream flow time series in the continental United States. Stoch. Environ. Res. Risk Assess. 2014, 28, 1685-1708. [CrossRef]

39. Stosic, T.; Telesca, L.; Ferreira, D.V.D.; Stosic, B. Investigating anthropically induced effects in streamflow dynamics by using permutation entropy and statistical complexity analysis: A case study. J. Hydrol. 2016, 540, 1136-1145. [CrossRef] 